\title{
Audit of thrombolysis initiated in an accident and emergency department
}

\author{
Patrick A Nee, Alistair J Gray, Michael A Martin
}

Accident and

Emergency

Department,

Stockport Infirmary,

Stockport SK1 3UJ

Patrick A Nee,

senior registrar

Alistair J Gray,

consultant

Stepping Hill

Hospital,

Poplar Grove,

Stockport SK2 7JE

Michael A Martin,

consultant physician and cardiologist

Correspondence to:

Dr P Nee, Accident and Emergency Department, Whiston Hospital, Prescot, Merseyside L35 5DR

Accepted for publication 1 November 1993

\begin{abstract}
Early thrombolytic therapy after acute myocardial infarction is important in reducing mortality. To evaluate a system for reducing in-hospital delays to thrombolysis pain to needle and door to needle times to thrombolysis were audited in a major accident and emergency ( $A$ and $E$ ) department of a district general hospital and its coronary care unit (CCU), situated about $5 \mathrm{~km}$ away. Baseline performance over six months was assessed retrospectively from notes of 43 consecutive patients (group 1) transferred to the CCU before receiving thrombolysis. Subsequently, selected patients (23) were allowed to receive thrombolysis in the $A$ and $E$ department before transfer to the CCU. The agent was administered by medical staff in the department after receiving oral confirmation of myocardial infarction from the admitting medical officer in the CCU on receipt of fax transmission of the electrocardiogram. A second prospective audit during six months from the start of the new procedure established time intervals in 23 patients eligible to receive thrombolysis in the $A$ and $E$ department (group 2b) and 30 ineligible patients who received thrombolysis in the CCU (group 2a). The groups did not differ significantly in case mix, pre-hospital delay, or transfer time to the CCU. In group $2 b$ door to needle time and pain to needle time were reduced significantly (geometric mean 38 $\min v 121 \mathrm{~min}$ (group 2a) and $128 \mathrm{~min}$ (group 1); $141 \mathrm{~min} v 237 \mathrm{~min}$ (group 2a) and 242 min (group 1) respectively, both $p<0.0001)$. The incidence of adverse effects was not significantly different. Nine deaths occurred (six in group 1, three in group 2b), an in-hospital mortality of $9 \cdot 9 \%$. Thrombolysis can be safely instituted in the $A$ and $E$ department in selected patients, significantly reducing delay to treatment.

(Quality in Health Care 1994;2:29-33)
\end{abstract}

\section{Introduction}

The importance of early administration of a thrombolytic agent after myocardial infarction is well established. The sooner that thrombolysis can be established, the greater the reduction in morbidity and mortality. ${ }^{12}$ Recent large studies showed no significant advantage of any one agent over another ${ }^{3}$; therefore, the main priority must be a reduction in the delay between the onset of chest pain and administration of the agent.

Significant loss of time often occurs in the prehospital phase, when an interval of four to six hours may elapse before the patient is seen by a doctor. ${ }^{5}$ This may be due to the patient's reluctance or inability to call for medical help. Education programmes for the public have achieved only limited success in reducing these delays. ${ }^{6}$

Some studies showed that thrombolytic therapy can be safely administered in the prehospital situation with potential time savings of about 60 minutes compared with treatment in hospital. ${ }^{7}$ However, until recently the available guidelines have recommended that the decision to administer a thrombolytic agent should be taken after transfer to hospital. ${ }^{8}$ Self referral and admission by emergency ambulance to the nearest accident and emergency (A and E) department save time when compared with calling a general practitioner. ${ }^{9}$

After admission to an A and E department a "fast track" triage system for certain categories of patients minimises delays in hospital. "Door to needle time" can be reduced to a median of 17 minutes. $^{10}$ However, the workload of the admitting officer and the time for assessment and documentation often lead to delays in transferring patients from the department to the coronary care unit (CCU) of more than 60 minutes, even when the two are in the same building. ${ }^{9}$ Therefore, the thrombolytic agent may be given in the $\mathrm{A}$ and $\mathrm{E}$ department before transfer to the CCU, usually by the cardiac care resident or admitting medical officer. Casualty officers are more likely to be immediately available than resident medical staff, but they may lack experience in interpreting the electrocardiogram. Consequently the decision to initiate thrombolysis is made solely by the A and $\mathrm{E}$ staff only in a minority of departments. ${ }^{11}$

Stockport Health District serves a mixed urban/rural population of over 300000 . The main district general hospital (Stepping Hill Hospital) has 796 beds, including six coronary care beds. The A and E department is located 
at Stockport Infirmary, a designated major unit, about $5 \mathrm{~km}$ away. Although most patients admitted to the CCU are sent in by their general practitioner, about a third present to the $\mathrm{A}$ and $\mathrm{E}$ department and are then transferred to the CCU by ambulance after assessment and immediate management by the casualty officers.

The main aims of this study were (a) to audit the various time intervals after the onset of chest pain in patients presenting to the A and $E$ department with suspected myocardial infarction who were then transferred to the CCU for thrombolytic therapy (group 1), (b) to institute a change - namely to allow the administration of the thrombolytic agent to selected patients within the $\mathrm{A}$ and $\mathrm{E}$ department (group 2), and (c) to re-audit the time intervals. The overall objective was to minimise in-hospital delays to thrombolytic therapy, ultimately to reduce mortality from myocardial infarction.

\section{Patients and methods}

AUDIT 1

We analysed retrospectively the records of 43 consecutive patients receiving thrombolytic agents in the CCU after transfer from the A and E department (group 1) for the six months from 1 February to 31 July 1991 . We recorded for each patient age, sex, date and time of admission to the $\mathrm{A}$ and $\mathrm{E}$ department and to the CCU, duration of chest pain before admission (pre-hospital delay), and the time at which infusion of streptokinase was commenced. We also recorded the incidence of subsequently proved myocardial infarction, the predominant site of the infarction, peak creatine kinase levels, systolic blood pressure on admission, and the incidence of heart failure. Finally, we recorded the incidence of arrhythmia, adverse reactions, and mortality in hospital. These data were obtained by reviewing the records of all patients who, according to the admission book of the CCU, were transferred from the $\mathrm{A}$ and $\mathrm{E}$ department during this period. The data were readily available from the case notes, which include both a photostat of the $\mathrm{A}$ and $\mathrm{E}$ record card and the patient's drug chart.

\section{INTERVENTION}

After agreement between the Cardiology and Accident Service's medical and nursing staff, all patients presenting to the $\mathrm{A}$ and $\mathrm{E}$ department after 1 October 1991 with symptoms suggesting myocardial infarction were managed as indicated (figure). The box lists the indications and contraindications for thrombolysis in the $\mathrm{A}$ and $\mathrm{E}$ department.

The junior staff in the department were all experienced in administering thrombolytic agents as they had all held previous junior house officer posts in general medicine. Oral and written instructions were available to them and the protocol (figure) was posted on the wall in the resuscitation area. Senior supervision was available on site at most times

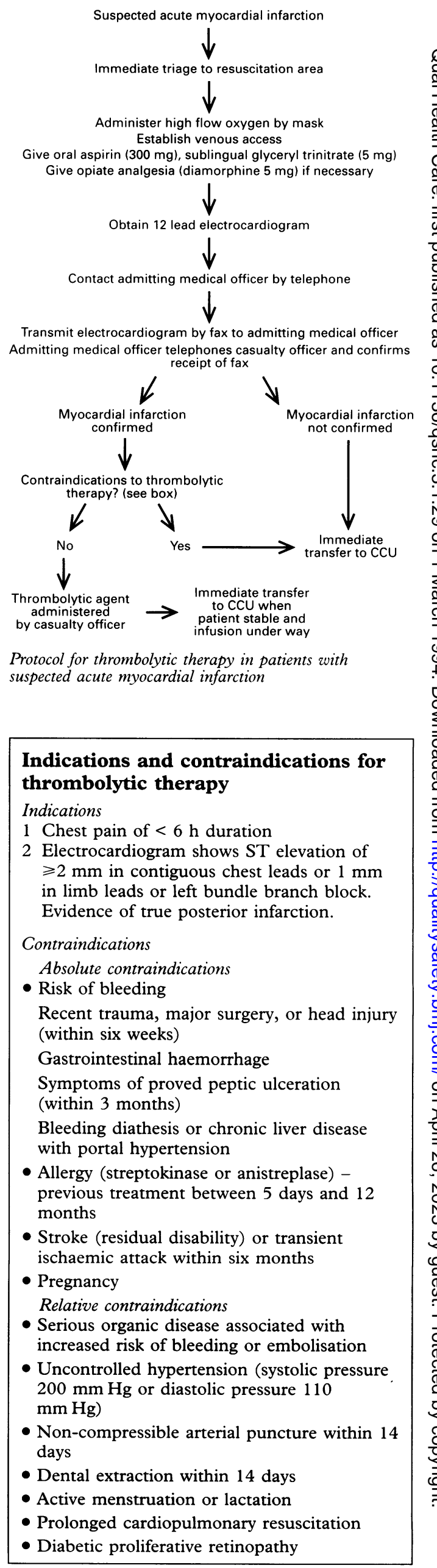


of the day, and advice was obtainable by telephone out of hours.

The first choice thrombolytic agent was streptokinase $(1.5 \mathrm{Mu})$, delivered with an infusion pump over one hour. Recombinant tissue plasminogen activator (RTPA) was used when the patient had been treated with streptokinase between five days and one year previously. Supplies of both streptokinase and RTPA were held in the resuscitation area. Fax machines are located within the department and in the CCU.

\section{AUDIT 2}

We carried out the second audit prospectively on consecutive patients transferred to the CCU from the $\mathrm{A}$ and $\mathrm{E}$ department during the six months from 1 October 1991 to 31 March 1992. This audit included 30 patients receiving thrombolysis in the CCU who were ineligible for treatment in the $\mathrm{A}$ and $\mathrm{E}$ department (group 2a) and 23 patients who received thrombolysis in the department (group 2b). The same audit indicators were recorded as for patients in group 1 .

Not all patients in the second audit group received the thrombolytic agent in the $\mathrm{A}$ and $\mathrm{E}$ department because of the requirement for a good history suggesting myocardial infarction and a diagnostic electrocardiogram. It was agreed between all parties that this new approach to administering thrombolysis required that treatment in the A and E department should be confined to those subgroups of patients known to benefit from early thrombolytic therapy that is, patients with recent onset of chest pain and ST elevation or left bundle branch block on electrocardiography. Those patients who fell outside these criteria were rapidly transferred to the CCU, where the decision on thrombolytic therapy was made at the discretion of the

Severity of myocardial infarction and intervals to thrombolytic therapy

\begin{tabular}{|c|c|c|c|c|}
\hline & $\begin{array}{l}\text { Audit 1 } \\
\text { (Group 1) }\end{array}$ & $\begin{array}{c}\text { Audit } 2 \\
\text { (Group 2a) }\end{array}$ & (Group 2b) & Significance \\
\hline $\begin{array}{l}\text { No of admissions } \\
\text { Mean (range) age (years) } \\
\text { No (\%) men }\end{array}$ & $\begin{array}{c}43 \\
59 \cdot 8(36-81) \\
32(74)\end{array}$ & $\begin{array}{c}30 \\
57 \cdot 5(38-73) \\
23(77)\end{array}$ & $\begin{array}{c}\quad 23 \\
57 \cdot 1(32-74) \\
19(78)\end{array}$ & \\
\hline \multirow{2}{*}{$\begin{array}{l}\text { No with proved myocardial infarction } \\
\text { Predominant site: } \\
\text { Anterior } \\
\text { Inferior } \\
\text { Indeterminate }\end{array}$} & 34 & 22 & 20 & \\
\hline & $\begin{aligned} 20 & (59) \\
13 & (38) \\
1 & (3)\end{aligned}$ & $\begin{aligned} 11(50) \\
11(50) \\
0(0)\end{aligned}$ & $\begin{array}{l}10(50) \\
9(45) \\
1(5)\end{array}$ & \\
\hline \multicolumn{5}{|c|}{ Peak creatine kinase level (Iu/) } \\
\hline $\begin{array}{l}\text { Geometric mean } \\
\text { Median } \\
\text { Range }\end{array}$ & $\begin{array}{c}1025 \\
1285 \\
44-6853\end{array}$ & $\begin{array}{c}762 \\
831 \\
64-3773\end{array}$ & $\begin{array}{c}1527 \\
1783 \\
111-6171\end{array}$ & \\
\hline \multicolumn{5}{|c|}{ Pre-hospital delay (min) } \\
\hline $\begin{array}{l}\text { Geometric mean } \\
\text { Median } \\
\text { Range }\end{array}$ & $\begin{array}{c}100 \cdot 0 \\
90 \\
30-440\end{array}$ & $\begin{array}{c}100 \cdot 7 \\
95 \\
25-430\end{array}$ & $\begin{array}{c}95 \cdot 7 \\
90 \\
30-325\end{array}$ & \\
\hline \multicolumn{5}{|c|}{$A$ and $E$ to $C C U$ interval (min) } \\
\hline $\begin{array}{l}\text { Geometric mean } \\
\text { Median } \\
\text { Range }\end{array}$ & $\begin{array}{c}76 \cdot 7 \\
70 \\
30-137\end{array}$ & $\begin{array}{c}69 \cdot 7 \\
65 \\
30-120\end{array}$ & $\begin{array}{c}82 \cdot 5 \\
85 \\
35-211\end{array}$ & \\
\hline \multicolumn{5}{|c|}{ Door to needle time (min) } \\
\hline $\begin{array}{l}\text { Geometric mean } \\
\text { Median } \\
\text { Range }\end{array}$ & $\begin{array}{c}128 \\
130 \\
65-360\end{array}$ & $\begin{array}{c}121 \\
118 \\
75-240\end{array}$ & $\begin{array}{c}38 \\
40 \\
15-90\end{array}$ & $\mathrm{p}<0.0001$ \\
\hline \multicolumn{5}{|c|}{ Pain to needle time (min) } \\
\hline $\begin{array}{l}\text { Geometric mean } \\
\text { Median } \\
\text { Range }\end{array}$ & $\begin{array}{c}242 \\
238 \\
125-580\end{array}$ & $\begin{array}{c}237 \\
220 \\
115-640\end{array}$ & $\begin{array}{c}141 \\
132 \\
48-359\end{array}$ & $\mathrm{p}<0.0001$ \\
\hline
\end{tabular}

resident medical officer. Initially we used an upper age limit of 75 years for patients whose thrombolysis was to be initiated in the department, but later this was abolished because of recent reports of favourable riskbenefit analyses of thrombolysis in elderly patients. ${ }^{12}{ }^{13}$ Transfers of patients between the department and the CCU were carried out by advanced trained ambulance crews, usually without medical staff in attendance.

\section{TIME VARIABLES}

Pre-hospital delay refers to the time from onset of chest pain to arrival in the $\mathrm{A}$ and $\mathrm{E}$ department. The A and E to CCU interval is the time from arrival in the department to the arrival in the CCU. The door to needle time is the interval from arrival in the $\mathrm{A}$ and $\mathrm{E}$ department to starting infusion of the thrombolytic agent, ${ }^{10}$ and finally, the "pain to needle time" is the sum of the pre-hospital delay and the door to needle time.

\section{STATISTICAL METHODS}

Patients' characteristics and time delays were computed with the statistical package for the social sciences (SPSS).${ }^{14}$ Categorical data were analysed by the $\chi^{2}$ test with two degrees of freedom and continuous variables by one factor analysis of variance together with Tukey's multiple range test. Statistical significance was ascribed at $\mathrm{p}$ values less than 0.05 .

\section{Results}

CASE MIX AND TIME VARIABLES

The three study groups did not differ significantly in terms of patient characteristics or site or severity of myocardial infarction (table). Prehospital delays were similar in all groups, and the time taken for transfer between the $\mathrm{A}$ and $\mathrm{E}$ department and the CCU was also similar. For patients eligible to receive the thrombolytic treatment in the department (group 2b), however, there were highly significant savings in the door to needle and pain to needle times; door to needle times were reduced by two thirds to a mean of 38 minutes (table).

\section{ADVERSE EVENTS}

Very few technical difficulties were associated with administering thrombolytic agents in the $A$ and $\mathrm{E}$ department before transfer. Generally, the electrocardiograms transmitted by fax were rapidly received by the admitting medical officer, and all were regarded as being of diagnostic quality.

The first few patients in group $2 b$ received streptokinase in a $100 \mathrm{ml}$ bag of saline through a giving set over one hour. In subsequent patients streptokinase was delivered through a $60 \mathrm{ml}$ syringe driver. Syringe drivers had been purchased in order to improve the precision of delivery, but in practice no line failures occurred in transit with either method of administration. 
Adverse events for which the likely cause was the thrombolytic treatment included arrhythmias (23\% of patients), symptomatic hypotension $(8 \%)$, bleeding or bruising $(4 \%)$, and flushing $(2 \%)$. The arrhythmias documented were sinus tachycardia and bradycardias, short runs of ventricular tachycardia or atrial fibrillation, and idioventricular rhythms and nodal rhythms. These were recorded within six hours of the infusion. Hypotension and flushing occurred at the time of the infusion and were recorded if they were sufficiently severe to cause the infusion to be slowed or stopped. Only one adverse event, an episode of hypotension, occurred in the A and E department. The thrombolytic agent was discontinued and the patient transferred immediately to the CCU with a doctor in attendance during ambulance transfer. No adverse events were recorded during transit for any patient. Bleeding or bruising noted within seven days was also noted. Some patients had more than one adverse event. The incidence of adverse events was not significantly different between the groups.

More serious complications included ten cases $(23 \%)$ of dangerous arrhythmia (prolonged ventricular tachycardia, ventricular fibrillation, complete heart block) in group 1 , $10(33 \%)$ in group $2 \mathrm{a}$, and five $(22 \%)$ in group $2 \mathrm{~b}$. The incidence of heart failure in the three groups was $13(30 \%)$, five $(17 \%)$, and five $(22 \%)$ cases respectively. No severe adverse events occurred during transit in patients in group 2b. All severe adverse events occurred later in the CCU.

Two patients who had received streptokinase, both in group $2 \mathrm{~b}$ had strokes, both non-haemorrhagic. There were nine deaths, six in group 1 and three in group $2 b$; overall mortality in hospital was therefore $9.9 \%$.

Prescription of thrombolytic agents to patients who were subsequently shown not to have had myocardial infarction was seen in nine patients $(21 \%)$ in group 1 , eight $(27 \%)$ in group $2 \mathrm{a}$, and three $(13 \%)$ in group $2 \mathrm{~b}$ $(p=0 \cdot 4)$.

\section{Discussion}

The split site arrangement in Stockport makes it impossible for patients to be seen rapidly in the $\mathrm{A}$ and $\mathrm{E}$ department by the admitting resident. For thrombolysis to be initiated in the department the responsibility must fall to the casualty officer. We addressed the problem of casualty officers interpreting electrocardiograms by the use of a fax machine, located in the $\mathrm{A}$ and $\mathrm{E}$ department, to transmit the trace to the CCU where it is read by the resident. We used the audit process to determine the efficiency and safety of this system.

Clinical audit has been recommended as a means of reducing in-hospital delays to thrombolysis. ${ }^{15}$ This study represents an appropriate model for the audit cycle in that a problem was identified, a change was instituted, and the results of that change were then evaluated. This study has small numbers of patients eligible to receive a thrombolytic agent in the $\mathrm{A}$ and $\mathrm{E}$ department. This reflects the strict criteria for admission to this group and could be improved by relaxing the admission criteria. Though it cannot be concluded from our study that time savings of this order (about one hour and 20 minutes) will have an impact on mortality, the reductions achieved in pain to needle times were similar to those reported in a recent study of pre-hospital treatment which did lead to improved mortality and morbidity. ${ }^{16}$ Our present study therefore represents an audit of a process of treatment that is known to reduce mortality.

The system of thrombolysis initiated in the A and E department is applicable not only when the CCU is located separately from the department but also when no CCU bed is available or when the admitting medical officer is unable to attend the department rapidly because of urgent commitments elsewhere. Fax transmission of the electrocardiogram allows the medical or cardiology service to maintain overall control, thereby reducing the likelihood of incorrect diagnosis. Our study showed that the system is efficient, electrocardiograms of diagnostic quality are received without delay by the admitting medical officer, and the decision to commence thrombolysis is quickly communicated back to the casualty officer by telephone. The incidence of inappropriate prescription of thrombolytic agents was seen less frequently in group $2 b$ than in the other two groups, again reflecting the strict criteria for admission to this group.

On the question of adverse events we noted predictable episodes, such as hypotension and minor bleeding, although these were infrequent and generally not clinically significant. The commonest adverse event was arrhythmia; however, it is impossible to say whether the disturbances in rhythm observed were due to reperfusion or to acute myocardial ischaemia. Arrhythmia induced by thrombolysis may be less common than previously appreciated, ${ }^{17}$ and, when it does occur, tends to be benign and self limiting.

The system of thrombolysis we have described is now used regularly and subject to further auditing periodically. We predict that such significant reductions in delays to thrombolysis will impact on mortality from myocardial infarction in Stockport.

We thank Ms J Morris for statistical advice, Ms V Bell for typing the manuscript, and the staff of the medical records department at Stepping Hill Hospital.

1 Gruppo Italiano per lo Studio della Streptochinasi nel 'Infarto Miocardico. GISSI Study Group. Long Term effects of intravenous thrombolysis in acute myocardial infarction: final reports of the GISSI study. Lancet 1987;ii:871-4.

2 The ISAM Study Group. A prospective trial of intravenous streptokinase in acute myocardial infarction (ISAM). Mortality, morbidity and infarct size at 21 days. $N$ Engl f Med 1986;314:1465-71.

3 Gruppo Italiano per lo Studio della Streptochinasi nell'Infacto Miocardico. GISSI -2 . A factoria randomised trial of alteplase versus streptokinase and acute myocardial infarction. Lancet 1990;336:65-71. 
4 The International Study Group. In-hospital mortality and clinical course of 20891 patients with suspected acute myocardial infarction randomised between alteplase and streptokinase with or without heparin. Lancet 1990;336:71-5.

5 Herve C, Gaillard M, Castaigne A, Jan F, Huguenard P. Thrombolysis at home. Lancet 1987; ii:278

6 Ho MT, Eisenberg MS, Litwin PE, Schaeffer SM Damon SK. Delay between onset of chest pain and seeking medical care: the effect of public education. Ann Emerg Med 1989;18:727-31.

7 European Myocardial Infarction Project (EMIP) Subcommittee. Potential time saving with pre-hospital intervention in myocardial infarction. Eur Heart $f$ 1988;9:118-24.

8 British Heart Foundation Working Group. Role of the general practitioner in managing patients with general practitioner in managing patients with myocardial infarction:

9 Pell ACH, Miller HC. Delays in admission of patients with acute myocardial infarction to coronary care: implications for thrombolysis. Health Bull 1990;48:225-31.
10 MacCullum AG, Stafford PJ, Jones C, et al. Reduction in hospital time to thrombolytic therapy by audit of policy guidelines. Eur Heart 7 1990;ii(suppl F):48-52.

11 Banerjee A. Thrombolytic therapy in A and E departments in the UK. Arch Emerg Med 1991;8:102-7.

12 Kennedy JW. Expanding the use of thrombolysis therapy for acute myocardial infarction. Ann Intern Med 1990;113:907-8

13 Grines CL, DeMaria AN. Optimal utilization of thrombolytic therapy for acute myocardial infarction: concepts and controversies. 7 Am Coll Cardiol 1990;16:223-31.

$14 \mathrm{Nie} \mathrm{N}$, Hull CH, Jenkins JE, et al. Statistical package for the social sciences. 2nd ed. New York:McGraw-Hill, 1975.

15 Cobbe SM. ISIS 3: the last work in thrombolysis? BMF 1992;304:1454-5.

16 GREAT Group. Feasibility, safety, and efficacy of domiciliary thrombolysis by general practitioners: Grampian region early anistreplase trial. $B M \mathcal{F}$ 1992;305:548-58.

17 Hackett D, McKenna W, Davies G, Maseri A. Reperfusion arrhythmias are rare during acute myocardial infarction and thrombolysis in man. Int $\mathcal{f}$ Cardiol 1990;29:205-13. 